\title{
ECHOCARDIOGRAPHIC SCREENING FOR DETECTION OF CONGENITAL HEART DEFECT IN ANORECTAL MALFORMATION
}

\author{
TALUKDER SA ${ }^{1}$, MAHMUD AA ${ }^{2}, \mathrm{KHAN} \mathrm{NZ}{ }^{3}$, BARI $\mathrm{MS}^{4}$, DAS SC ${ }^{5}$, BARI $\mathrm{MS}^{6}$
}

\begin{abstract}
:
The aim the study was to evaluate association of congenital heart defect in patient having anorectal malformation by echocardiography and to find out the incidence of congenital heart defect associated with anorectal malformation (ARM). A total of 60 patients were studied in the Department of Paediatric Surgery in Mymensingh Medical College Hospital, Mymensingh, between July 2010 and October 2011, with age ranging from 1-120 days. The mean age was 0.49 \pm 1.002 months. Male female ratio was 1.6:1. Among the 60 patients 36(60\%) were high and 24(40\%) were low variety of ARM. Associated cardiac anomalies were 10(16.67\%) with 1 symptomatic and remaining 9 were asymptomatic. most common cardiac anomalies were ventricular septal defect (VSD) 5 followed by atrial septal defect (ASD) 2, patent foramen ovale 2 and patent ductus arteriosus 1. Among the cardiac anomalies, 8(80\%) were with high and 2(20\%) with low variety of ARM. All asymptomatic patients were underwent surgical intervention with a team consist of cardiologist, neonatologist, paediatric surgeon and ICU supports taking very cautiousness perioperative care to reduce the morbidity and mortality and recovered uneventfully. Symptomatic patient was referred to specialized center for more careful management.
\end{abstract}

Key words: echocardiography, congenital heart defect, anorectal malformation.

J Dhaka Med Coll. 2012; 21(2) : 184-187.

\section{Introduction:}

Anorectal malformations are complex group of malformation diagnosed at time of birth because of absence or an ectopic location of anus. The incidence is approximately 1:5000 live births and they are more often seen in boys than in girls ${ }^{1}$. Anorectal malformations are associated in a high percentage of patients with other anomalies $^{2}$. The VATER association is a spectrum of associated defects designating vertebral defects, anal atresia, renal, tracheoesophageal fistula with esophageal atresia, defects and radial limb dysplasia. The scope of association has also been enlarged to include cardiac anomalies by using term VACTERL to denote the association; with $\mathrm{C}$ referring to cardiovascular anomalies and L to limb defects ${ }^{3}$. The associations are more common in high ARM than low ARM. Many of these associated anomalies are serious and the long term prognosis of child with anorectal malformation is often more dependent on the extent of these associated anomalies than on the anorectal malformation itself. Early detection of such anomalies is important ${ }^{4}$. Not only is the knowledge of functional anatomic variations important in the management of these conditions, but also a thorough understanding of the associated anomalies is necessary ${ }^{5}$. The surgical and medical management of patients with these malformations may be complex, especially when one considers the high

1. Prof. Md. Shah Alam Talukder, Professor \& Head, Dept. of Paediatric Surgery, Mymensingh Medical College \& Hospital, Mymensingh.

2. Dr. Md. Abdullah Al Mahmud, Assistant Registrar, Dept. of Paediatric Surgery, Mymensingh Medical College Hospital, Mymensingh.

3. Dr. Nadiuzzaman Khan, Registrar, Dept. of Paediatric Surgery, Mymensingh Medical College Hospital, Mymensingh.

4. Dr. M. Saiful Bari, Associate Professor \& Head, Dept. of Cardiology, MMCH,

5. Dr. Shankar Chandra das, Medical Officer, Gazipur Sadar Hospital, Gazipur.

6. Dr. Md. Shafiqul Bari, Registrar, Dept. of Paediatric Surgery, Mymensingh Medical College Hospital, Mymensingh. Correspondence: Prof. Md. Shah Alam Talukder, Professor \& Head, Dept. of Paediatric Surgery, Mymensingh Medical College \& Hospital, Mymensingh. Email:doctorshahalam@gmail.com 
frequency of concomitant anomalies that occur with $\mathrm{ARM}^{6}$. A complete diagnosis is important when counseling the parents of neonates with multiple complex malformations before surgery is contemplated ${ }^{7}$. Cardiac anomalies were defined as ventricular septal defect(VSD), atrial septal defect (ASD),Tetralogy of Fallot( TOF), atrioventricular septal defect( AVSD), persistent ductus arteriosus (PDA), Coarctation of the aorta, double outlet right ventricle ( DORV) , left atrioventricular valve ( LAVV). ASD is the most common then PDA and VSD are the next most common findings ${ }^{7}$. Most of the cardiac anomalies except some severe form are asymptomatic in neonatal period ${ }^{8}$. Early diagnosis, management of associated anomalies, and efficient meticulous surgical repair provide patients the best chance for a good functional outcome ${ }^{9}$. Early diagnosis of such asymptomatic associated cardiac anomalies could be possible by Echocardiographic screening in patient having ARM. The present study is expected to help to early diagnosis of congenital heart defect in ARM patient and guide to proper management and thus help to reduce the morbidity, mortality and better outcome in patients with ARM.

\section{Methods:}

This cross sectional study was conducted in a teaching hospital between July 2010 and October 2011. A total of 60 patients were selected in the department of paediatric surgery during this period age ranging from 1-120 days with the mean age of $0.49 \pm 1.002$ months. Male female ratio was 1.6:1. A total number of 65 patients of who were admitted in the Department of Paediatric Surgery in Mymensingh Medical College Hospital, Mymensingh, through the emergency department with the complaints of anorectal malformation were selected for this study. Among them 5 patients were excluded from this study due to extensive co-morbidity. Finally 60 patients were included in this study. All the patients included in this study were evaluated through proper clinical history, careful physical examination and relevant investigations after primary resuscitation. To detect the type of anorectal malformations, invertogram and transperineal ultrasonography were done, for those who were not clinically confirmed. To ascertain the cardiac status, presence or absence of CHD, type of CHD, color doppler echocardiography was done at an earliest possible time in every case irrespective of clinical findings. All asymptomatic patients were underwent surgical intervention with a team consist of cardiologist, neonatologist, paediatric surgeon and ICU supports taking very cautiousness perioperative care to reduce the morbidity and mortality and recovered uneventfully. Symptomatic patient was referred to specialized center for more careful management.

\section{Results:}

Among the 60 cases, 36(60\%) were diagnosed as high variety and $24(40 \%)$ were diagnosed as low variety ARM. Here associated cardiac anomalies were found in 10(16.67\%), limb defect in $3(5 \%)$, vertebral in $1(1.67 \%)$ and urinary in $1(1.67 \%)$. Associations were more with high ARM which is highly significant $(\mathrm{p}<0.01)$ (Table-I). Among the 60 cases, maximum associated cardiac anomalies were VSD 5(50\%), followed by ASD 2(20\%), patent foramen ovale $2(20 \%)$ and PDA $1(10 \%)$. Associated CHD were more in high ARM but statistically not significant ( $p>0.05)$ (Table-II).

Table-I

Associated anomalies in ARM $(n=60)$

\begin{tabular}{lccccc}
\hline Types ofARM & Cardiac & Verte-bral & Urinary & Limb-defect & Total \\
\hline High & $8(13.33 \%)$ & 0 & 0 & $2(2.34 \%)$ & $10(16.67 \%)$ \\
Low & $2(2.34 \%)$ & $1(1.67 \%)$ & $1(1.67 \%)$ & $1(1.67 \%)$ & $5(8.33 \%)$ \\
Total & $10(16.67 \%)$ & $1(1.67 \%)$ & $1(1.67 \%)$ & $3(5 \%)$ & $15(25 \%)$ \\
\hline P value & & & & $0.0054^{* *}$ \\
\hline
\end{tabular}

Chi-square test, ${ }^{* *}=$ significant, $\mathrm{p}<0.01$, df. $3, \div 2=6.850$ 
Table-II

Types of cardiac anomalies associated with ARM $(n=10)$

\begin{tabular}{|c|c|c|c|c|c|c|}
\hline \multicolumn{3}{|c|}{ Types of ARM } & \multicolumn{3}{|c|}{ Types of CHD } & \multirow[t]{2}{*}{$\mathrm{P}$ value } \\
\hline & ASD & VSD & PDA & PF; Ovale & Total & \\
\hline High & $2(20 \%)$ & $4(40 \%)$ & $1(10 \%)$ & $1(10 \%)$ & 8 (80\%) & $0.588 \mathrm{~ns}$ \\
\hline Low & 0 & $1(10 \%)$ & 0 & $1(10 \%)$ & 2 (20\%) & \\
\hline Total & $2(20 \%)$ & $5(50 \%)$ & 1 (10\%) & $2(20 \%)$ & 10 (100\%) & \\
\hline
\end{tabular}

Chi-squire test, df. $3, \div 2=0.639$, ns $=$ Not significant

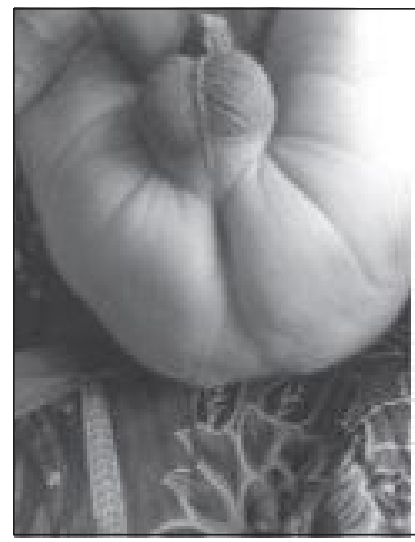

Fig.-1. A) High ARM

B) Low ARM

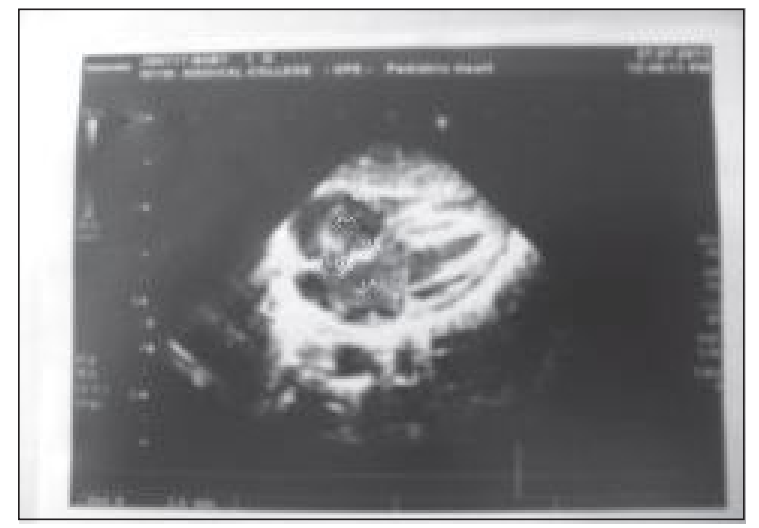

Fig.-3. High ARM Associated with ASD.

Table-IV

A comparative Incidence of cardiac anomalies associated with anorectal malformations in various series

\begin{tabular}{lcc}
\hline Author(s) & Year & Percentage \\
\hline Greenwood et al. $^{12}$ & 1975 & 11.7 \\
Hoekstra et al. $^{13}$ & 1983 & 12.0 \\
Tulloh RMR et al. $^{7}$ & 1994 & 23.0 \\
Hasink et al. $^{14}$ & 1996 & 21.0 \\
Mittal et al. $^{4}$ & 2004 & 12.14 \\
Present study & 2012 & 16.67 \\
\hline
\end{tabular}



Fig.-2: High ARM Associated with VSD.

\section{Discussion:}

Anorectal malformations comprise a wide spectrum of diseases, which can affect boys and girls, and involve the distal anus and rectum as well as the urinary and genital tracts. Defects range from the very minor and easily treated with an excellent functional prognosis, to those that are complex, difficult to manage, are often associated with other anomalies, and have a poor functional prognosis ${ }^{9}$. The incidence is slightly higher in male ${ }^{10}$. There is a different group of associated anomalies present with ARM. Associated anomalies are more common in high than low level deformities ${ }^{11}$. Mittal et al. ${ }^{4}$ in their study observed, the associated anomalies were more in high $(78.08 \%)$ than low $(37.31 \%)$ variety of ARM. Associated anomalies with the incidence of urinary system (37.14\%), vertebral (34.2\%), skeletal other than vertebral $(15.17 \%)$, genital (14.29\%), cardiovascular system (12.14\%), gastrointestinal $(10.7 \%)$ and spinal cord $(10 \%)$. In this study we also found associated anomalies were more in high $10(16.67 \%)$ than low $5(8.33 \%)$ variety of ARM which is 
statistically significant $(\mathrm{p}<0.01)$ and associated cardiac anomalies were $10(16.67 \%)$. In their study they screen the relevant associated anomalies among which cardiac anomaly was $(12.14 \%)$ which is more or less consistent with the present study.

Greenwood et al. ${ }^{12}$ observed that the most common associated cardiac anomalies were Tetralogy of Fallot and ventricular septal defect. Mittal et al. ${ }^{4}$ also found that the most common associated cardiac anomaly was Tetralogy of Fallot (6) followed by ventricular septal defect (5). Our study showed most common associated cardiac anomalies were ventricular septal defect (5) followed by atrial septal defect (2), patent foramen ovale (2) and patent ductus arteriosus (1). In their study, ventricular septal defect (VSD) was the second highest, but in our study highest in number. The associated cardiac anomalies were more in high 8 $(13.33 \%)$ than low 2(3.34\%) variety of ARM but there were no significant difference of associations with types of ARM ( $p>0.05)$.

Echocardiographic screening in ARM patients enables to detect occult CHD, confirmed obvious CHD including their types and thereby formulate management plan at an earliest period of time. Sample size was small and purposive, single centered study, Echocardiography could not be done all cases as an emergency basis all these limitalized the present study.

\section{Conclusion:}

Echocardiography can detect congenital heart disease at an earliest period of time and thereby help to formulate management plan to reduce the morbidity and mortality in ARM patients. This sort of study may increase the awareness of associated life threating anomalies at the earliest opportunity.

\section{References:}

1. Stringer D. Pediatric large bowel. In: Freeney PC, Stevenson GW, eds. Margullis and Burhenne's
Alimentary Tract Radiology. $5^{\text {th }}$ ed. Philadelphia: Mosby; 1994. p.1909-91.

2. Starer F, Mireaux CD. The pediatric abdomen. In: Sutton D, Whitehouse RW, Jenkins JPK Davies ER, Murget J, Lees WR, eds. Textbook of Radiology and Imaging. $6^{\text {th }}$ ed. New York: Churchill Livingstone; 1998. p.1094-6.

3. Khoury MJ, Cortero JF, Greenberg F, Lames LM, Erickson JO. A population study of the VACTERL association: evidence for its etiologic heterogeneity. Pediatrics 1983; 71: 815-20.

4. Mittal A, Airon RK, Magu S, Rattan KN, Ratan SK. Associated anomalies with anorectal Malformation (ARM). Indian J Paediatr 2004; 71 : 505-14.

5. Weiner ES, Kiesewetter WB. Urologic abnormalities associated with imperforate anus. J Pediatr Surg 1973; 8: 151-7.

6. Pena A. Imperforate anus and Cloacal malformations. In: Ashcraft KW. ed. Paediatric surgery. $3^{\text {rd }}$ ed. Philadelphia: WB Saunders; 2000. p.456-92.

7. Tolloh RMR, Tansey SP, Parashar K, DeGiovanni JV, Wright JGC, Silove ED. Echocardiographic screening in neonates undergoing surgery for selected gastrointestinal malformations. Arch Dis Child 1994; 70: 206-8.

8. Khan MR, Rahman ME. Cardiovascular diseases In: Essentials of paediatrics. $2^{\text {nd }}$ ed. Dhaka: 1995. p.153-65.

9. Levitt MA, Pena A. Anorectal malformations. Orphanet J Rare Dis 2007; 2: 1-13.

10. Vaishali S, Ray AK, Patra R, Saha BK, Samanta N, Saha K. Urogenital anomalies associated with anorectal malformation. IAPS 2005; 10: 44-7.

11. Belman BA, King LR. Urinary tract anomalies associated with imperforate anus. J Urol 1982; 108: p.823-4.

12. Greenwood RD, Rosenthal A, Nadas AS. Cardiovascular malformations associated with imperforate anus. J Pediatr 1975; 86: 576-9.

13. Hoekstra WJ, Scholtmeijer RJ, Molenaar JC, Schreeve RH, Schroeder FH. Urogenital tract abnormalities associated with congenital anorectal anomalies. J Urol 1983; 130: 962-3.

14. Hassink EAM, Rieu PNMA, Hamel BCJ, Severijnen RSVM, Staak FHJV, Festen C. Additional congenital defects in anorectal malformations. Eur J Pediatr 1986; 155: 477-82. 